\title{
Data Format and Interface Design in Digital Identity Applications Using WSO2
}

\author{
Yuki Indragiri Winata ${ }^{* 1}$, Hermawaty ${ }^{2}$, Muh Mujib ${ }^{3}$ \\ ${ }^{1,2,3}$ Program Studi Sistem Informasi, STMIK AMIK B ANDUNG \\ E-mail: " ${ }^{\text {1 }}$ ukiindragiriwinata@gmail.com \\ ²emma@stmik-amikbandung.ac.id, ${ }^{3}$ abdul.mujib@stmik-amikbandung.ac.id
}

\begin{abstract}
This study aims to upgrade the application login system in STMIK "AMIKBANDUNG", from some problems that exist in a regular login system and with the development of an information system that requires STMIK "AMIKBANDUNG" to follow its development, not only various applications but companies are required to improve data security on the application login system.

In the draft in this study proposes a single entry system (Single Sign On). By using this single login system, users only need to remember one user name and password to enter in various applications in the organization or company.

In this study using open source WSO2 IS, and in the database system in WSO2 IS there is an embedded database system that is H2 database, in addition to H2 database, WSO2 IS provides a place for other database systems such as MYSQL. So in one identity provider this contains two database systems. And the results of the application of MYSQL database in this research allows WSO2 IS users to develop in various protocols in WSO2 IS, and use a simple and easy to understand interface format.

So with this research, STMIK "AMIKBANDUNG" can upgrade the login system, with only one account can make it easier for students and staff to enter into one or more of the application services in STMIK "AMIKBANDUNG".
\end{abstract}

Keywords — Single Sign On, Database Working, MYSQL, WSO2 Identity Server.

\section{INTRODUCTION}

STMIK Campus "AMIKBANDUNG" is a computer science campus, the study programs there are Informatics Engineering, Information Systems and Visual Communication Design. The Informatics Engineering Study Program aims to produce graduates in the field of informatics who are able to plan, design and implement an integrated system to solve information technology problems in various fields such as education, banking, telecommunications, manufacturing, or other industries. While the Information Systems (IS) study program is a study program that studies how to design the right system based on the goals of the organization or company in accordance with business needs and processes. This program is designed to meet the need for skilled and professional young workers, especially those related to the development, utilization, and management of Information Systems/Information Technology within an organization.

STMIK "AMIKBANDUNG" has a website-based service system, the website is useful for conducting guardianship or course contracts, value information, class schedules, etc. In addition to having a website for information services, STMIK "AMIKBANDUNG" has a website-based online class, useful for helping students find information on assignments from their lecturers and making it easier for students to get maximum grades. 
Based on the background of the problem, the authors can take the main problems that exist on the STMIK "AMIKBANDUNG" campus, where the campus does not yet have a single sign on system, in order to make it easier for users of information system services on the STMIK "AMIKBANDUNG" campus just by making one accounts for various existing information service systems or online classes

\section{RESEARCH METHOD}

The method used is the kanban method. Kanban is an agile methodology that focuses on visualizing workflows. Workers in teams who use the kanban method receive assignments and materials exactly when they are needed. The way Kanban works is divided into prioritized tasks and entered into the backlog. The relationship in research with the Kanban method will be explained in the following table:

Table 2.1. Kanban Method

\begin{tabular}{|c|l|c|c|}
\hline No & \multicolumn{1}{|c|}{ To Do } & Progress & Done \\
\hline 1. & $\begin{array}{l}\text { Designing a data system (single sign on) for } \\
\text { each member whose identity is stored in a } \\
\text { digital identity database }\end{array}$ & Planning & $\checkmark$ \\
\hline 2. & Applying the database system design. & Planning & $\checkmark$ \\
\hline 3. & Designing application interfaces & Planning & $\checkmark$ \\
\hline 4. & Implement the application interface design & Implementation & $\checkmark$ \\
\hline
\end{tabular}

Design Workflow:
a. Case Study
b. Data Setup
c. Data Implementation
1) Create a Database Design
2) Implement Database Design
3) Implement Interface Design

d. Testing

\section{RESEARCH RESULTS AND DISCUSSION}

In this section, we will explain the design flow as well as the analysis that will be carried out using the Kanban method in:

1) analyze a database system.

2) Create a database system design.

3) Analyze interfaces.

4) Create an interface design. 
Table 3.1. WSO2 Identity Server Analysis and Design

\begin{tabular}{|c|c|c|c|}
\hline No & To Do & Progress & Done \\
\hline 1. & $\begin{array}{l}\text { Single sign on (SSO) } \\
\text { database system for } \\
\text { each member whose } \\
\text { identity is stored in a } \\
\text { digital identity database }\end{array}$ & 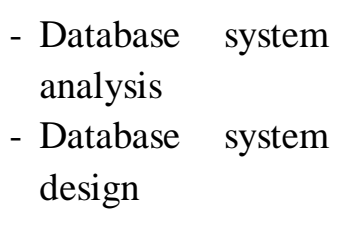 & $\checkmark$ \\
\hline 2. & $\begin{array}{l}\text { Wso2 identity server } \\
\text { application interface }\end{array}$ & $\begin{array}{l}\text { - Application } \\
\text { Interface Analysis } \\
\text { - Application } \\
\text { interface design }\end{array}$ & $\checkmark$ \\
\hline
\end{tabular}

Designing a single sign on (SSO) data system for each member whose identity is stored in a digital identity database

\section{Database System Analysis}

WSO2 Identity Server ships with an embedded H2 database to store data. This default database is located in the <IS_HOME>/repository/databased product package directory.

a. Default database

Described below are the default databases that you will find in the database directory.

1) Identity database : WSO2IDENTITY_DB.mv.dbWSO2 Identity Server owns this database data regarding its specific identity.

2) Shared database: this WSO2SHARED_DB.mv.db database contains registry and user management data.

3) Carbon database: This WSO2CARBON_DB.mv.db database has internal data related to the product. This data is stored in the embedded $\mathrm{H} 2$ database.

4) Workflow database: This jpadb.mv.db database has workflow related data.

The following image shows the default databases and the data stored in each database.
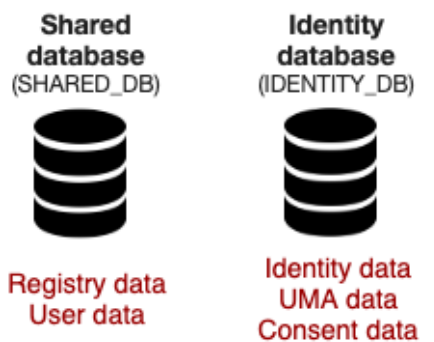

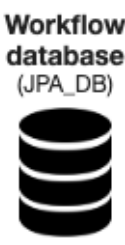

Workflow data
Carbon

database (CARBON_DB)

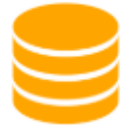

Internal server data

Figure 3.1. wso2 identity server default database

\section{Database System Design}

WSO2 Identity Server uses a database to store information such as user management details and identity data. By default, every WSO2 product ships with an embedded $\mathrm{H} 2$ database that works for all types of data. 
This section walks you through the logical data splits you can perform when grouping WSO2 Identity Servers.

The following figure shows the default database structure and the recommended database structure for logical data separation.

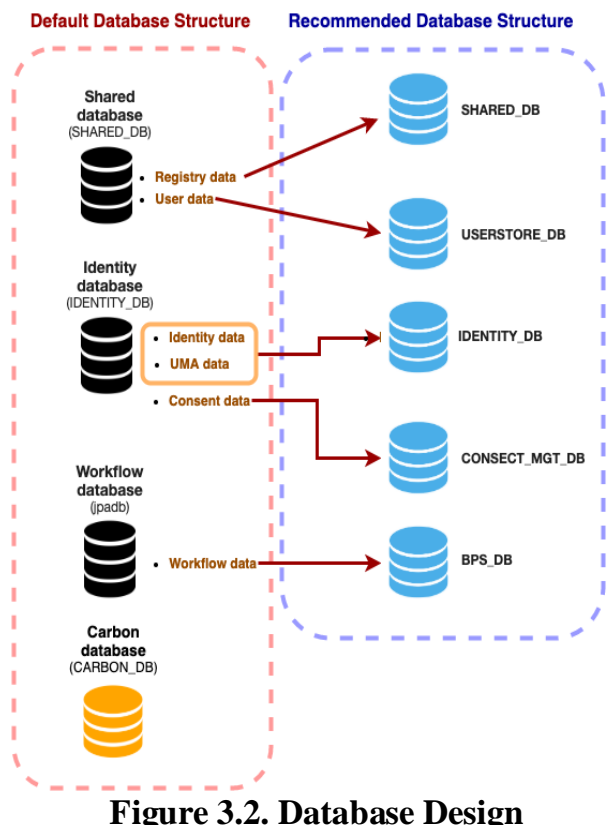

Figure 3.2. Database Design

Designing the wso2 identity server application interface. Wso2 identity server management console interface analysis

WSO2 Identity Server Management Console is a Web Based User Interface. This allows users to interact with a running Identity Server instance, without having to intervene with the underlying configuration files. The controls in the Management Console are usually self-explanatory. This page provides an overview of the management console User Interface.

a. Wso2 identity server main server view

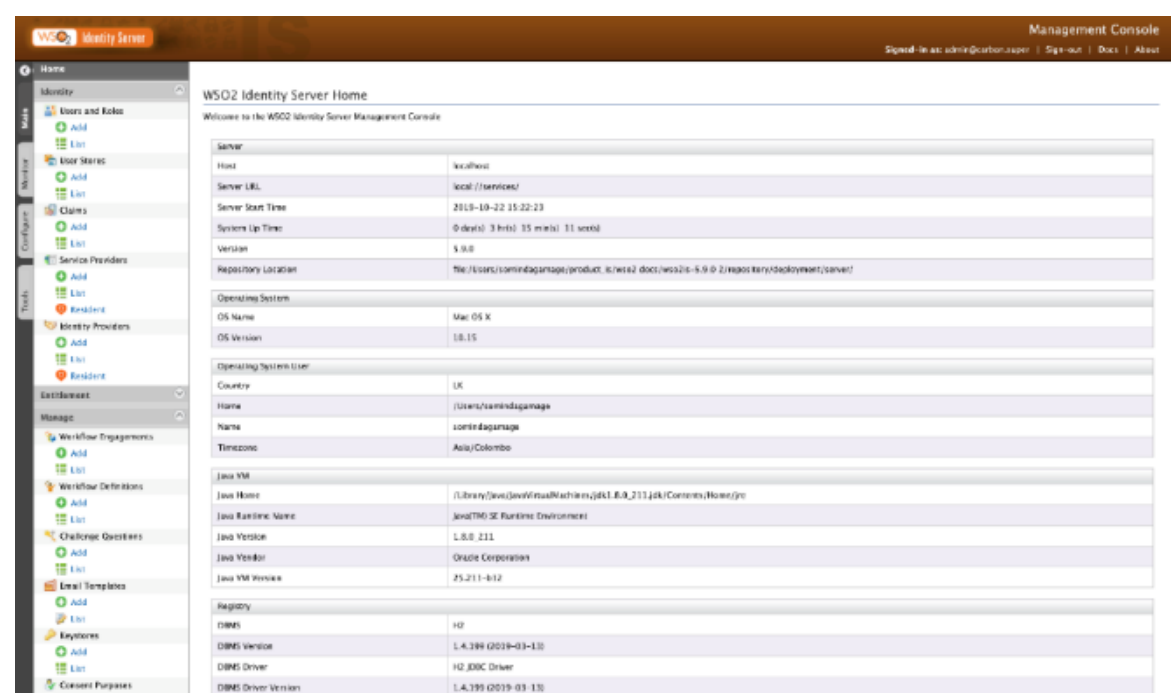

Figure 3.2. Management Console wso2 identity server 
b. Main Course

The main menu in the Management Console includes the main list of features that the WSO2 Identity Server provides. The main menu is divided into several sections.

c. Identity Part

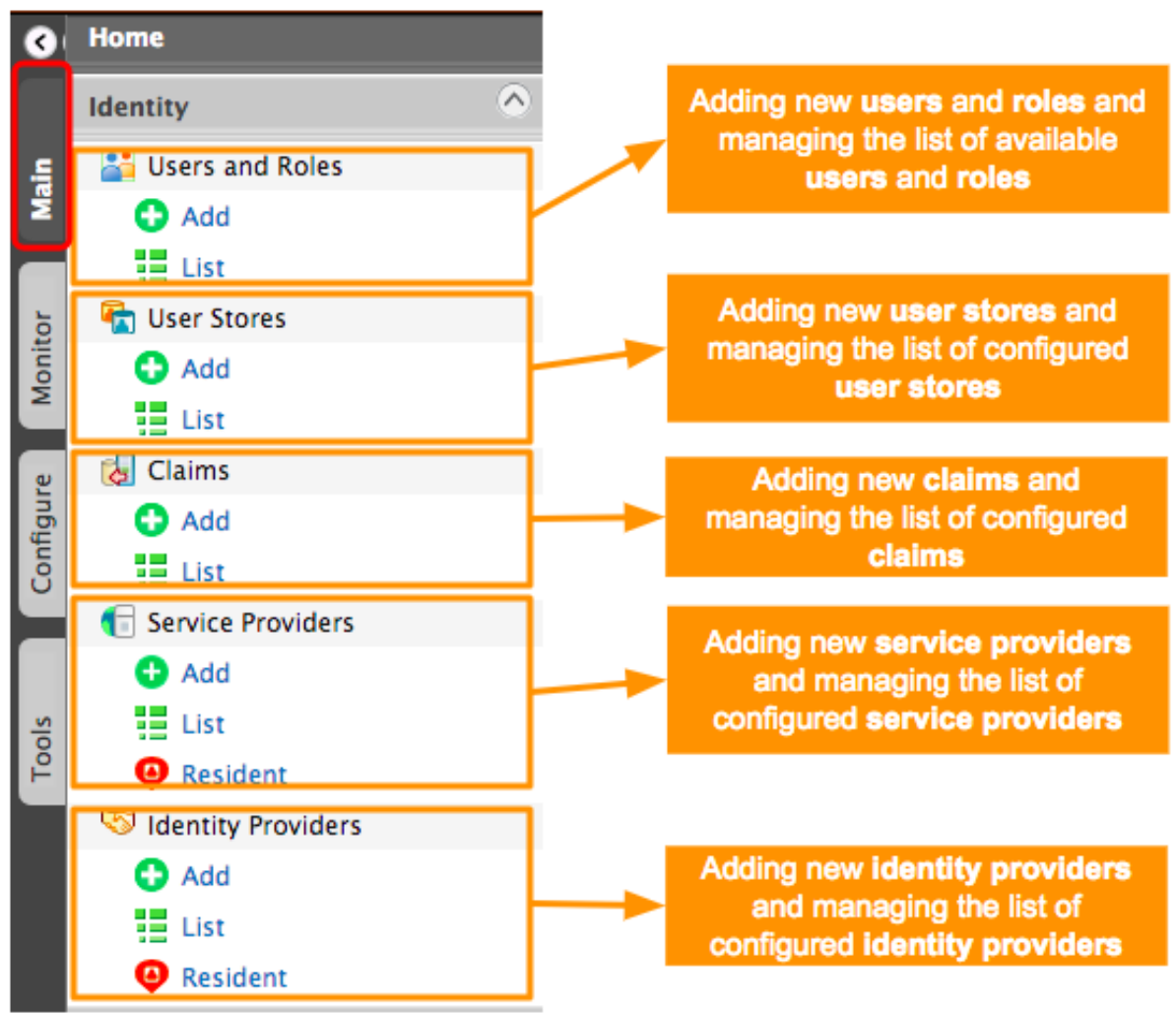

Figure 3.3. WSO2 Identity Tools

d. Rights Share

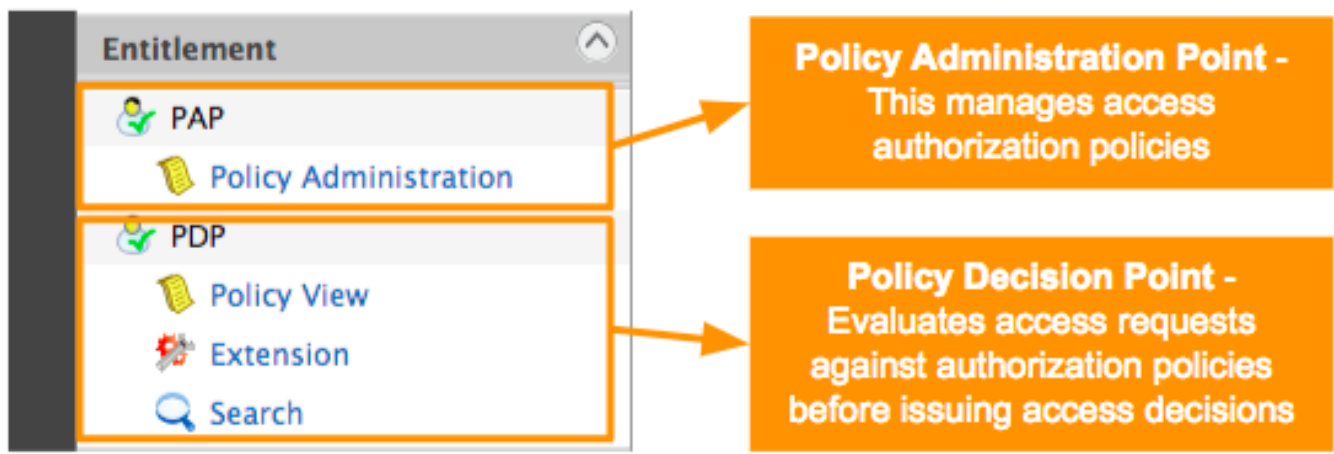

Figure 3.4. WSO2 Entitlement 
e. Manage Sections

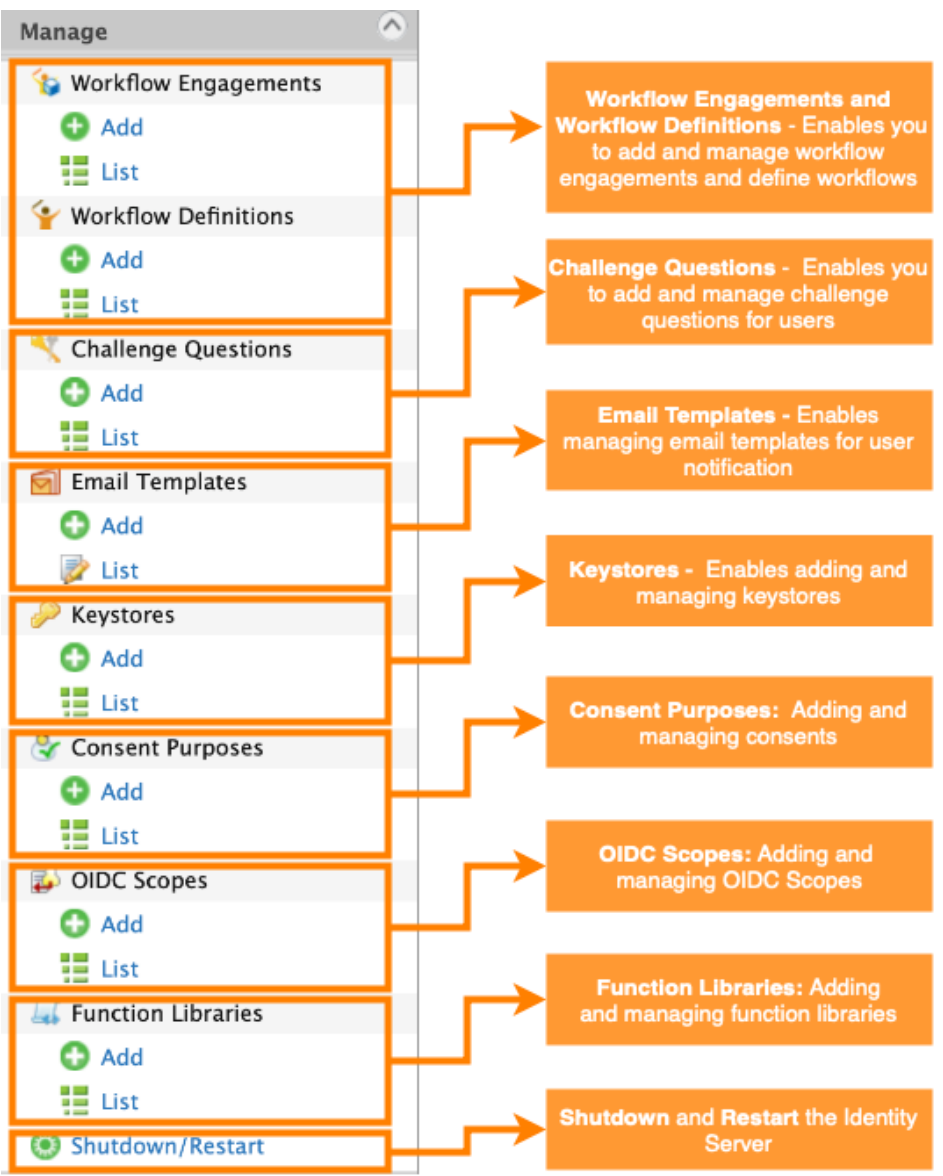

Figure 3.5. Manage section WSO2 Identity server

f. Monitor Menu

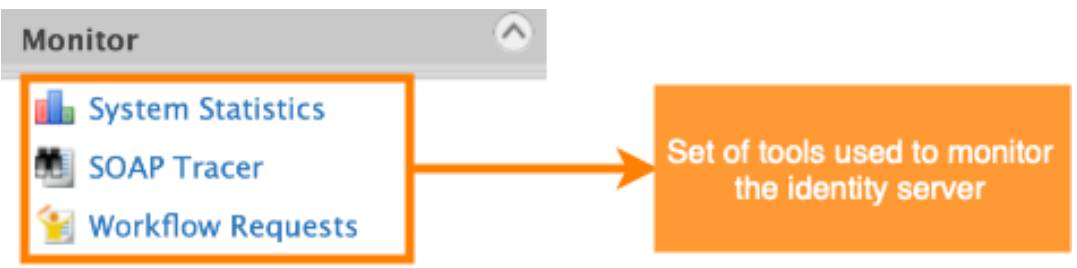

Figure 3.6. monitoring tools

g. Menu Configuration

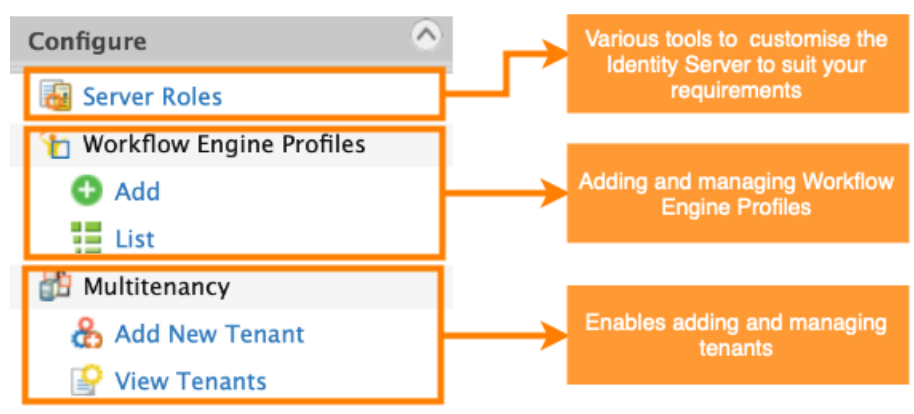

Figure 3.7. Tools Menu 
h. Tools menu

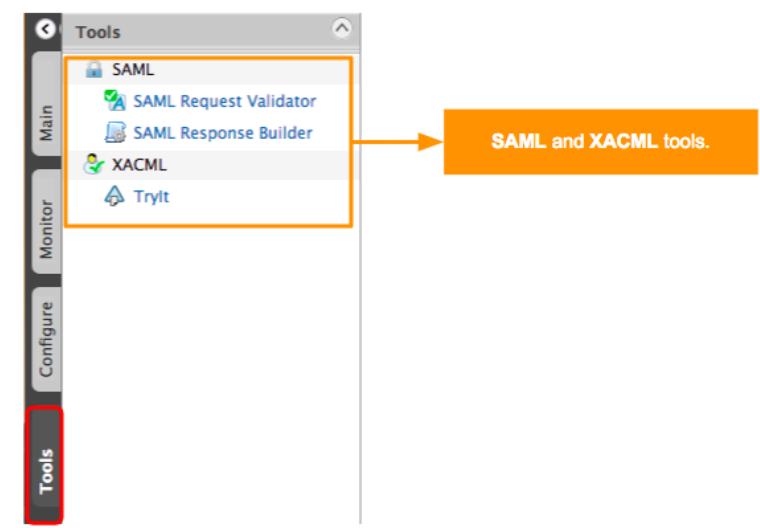

Figure 3.8. tools

\section{Application Sample Interface Design}

1) Display login form saml2-info-amik.com

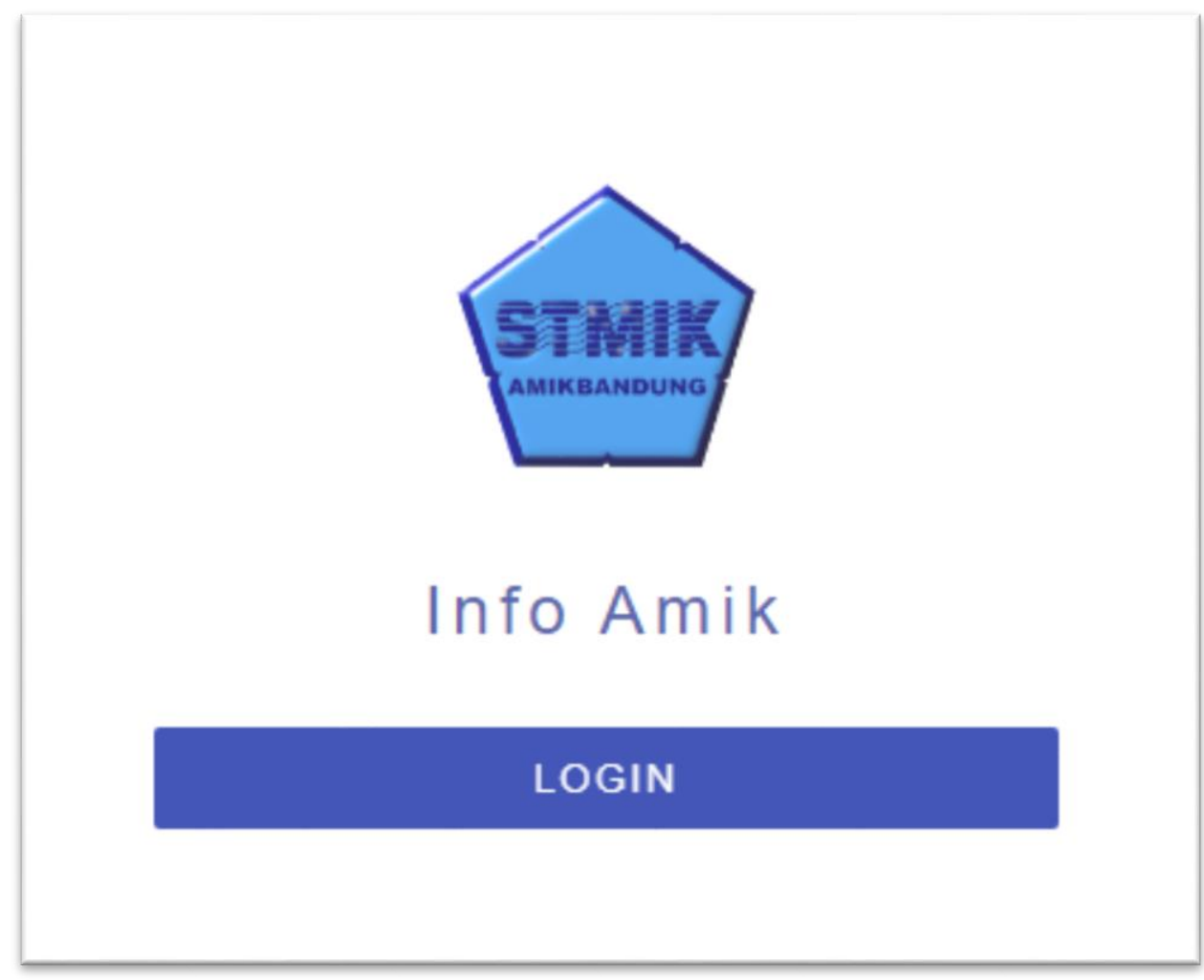

Figure 3.9. Sample interface of Amik Info Login Form 
2) Display login form saml2-lms-amik.com

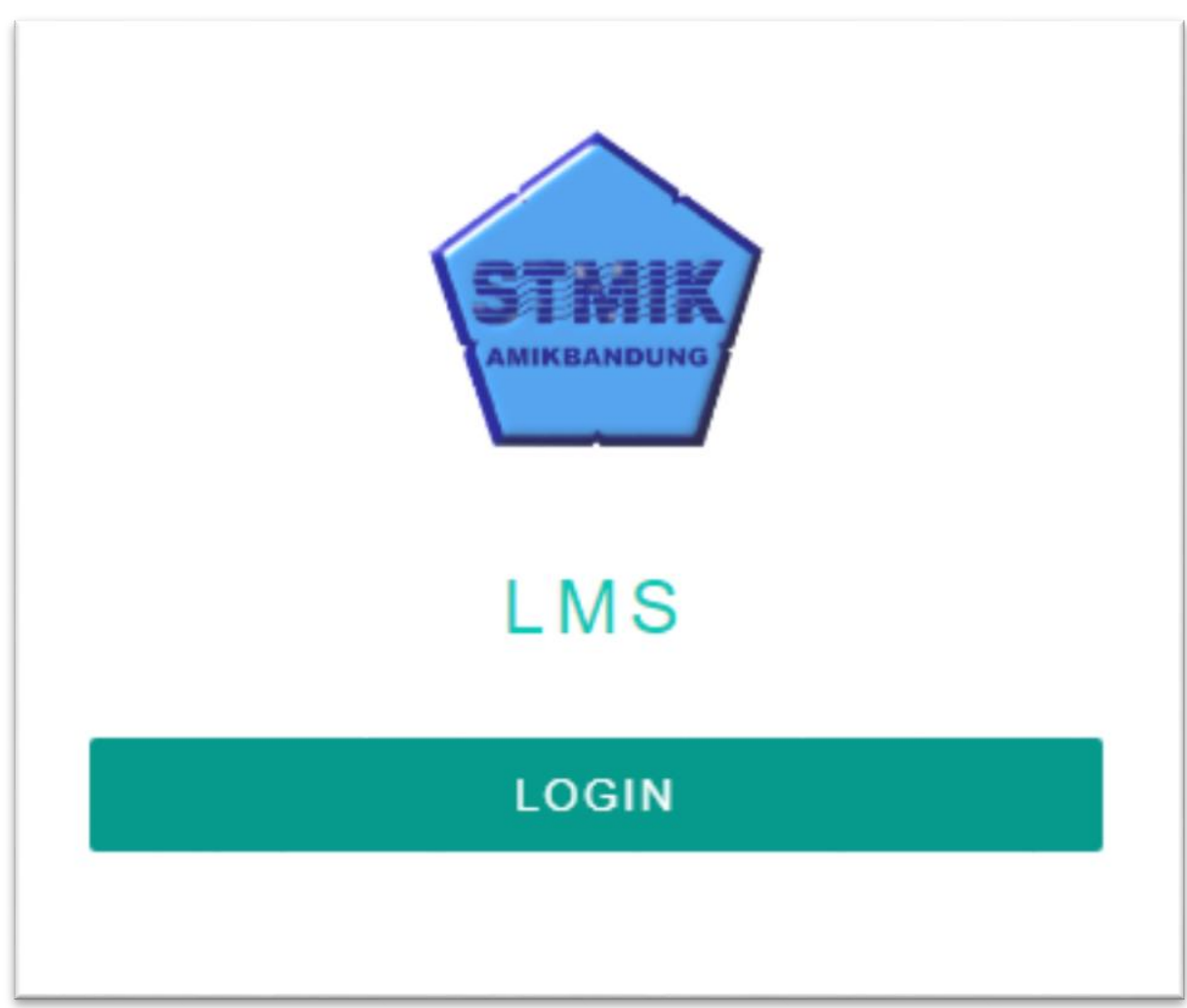

Figure 3.10 LMS Login Form Sample Interface

3) Home screen saml2-info-amik.com

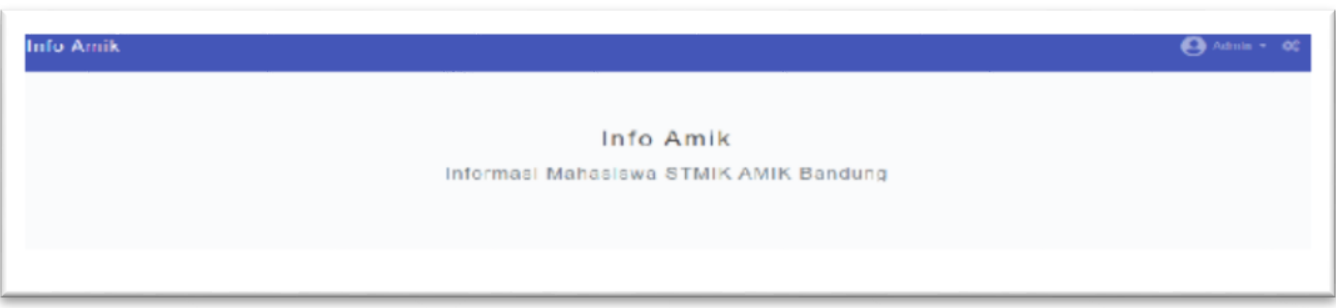

Figure 3.11. Sample Home Info Amik

4) Home screen saml2-lms-amik.com

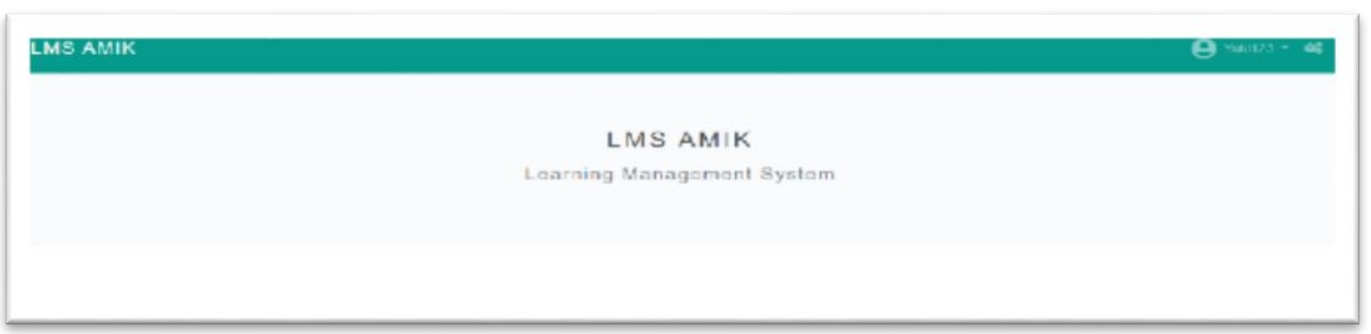

Figure 3.12. Sample Home LMS Amik 


\section{CONCLUSION}

Based on the results of the study, the authors draw the following conclusions:

1) By adding another database other than the default database on the wso2 identity server, apart from backing up data, data storage will be more secure.

2) A digital identity information system with a single sign-on method has been configured in the application.

3) This system is built using identity providers from the wso2 identity server.

\section{SUGGESTED}

There are several suggestions that the author wants to put forward to develop the system that has been made as follows:

1) With the implementation of the addition of this database, the author gives advice to anyone who uses it to be able to change to a better database.

2) And the author hopes that in the future, there will be more who can develop the interface so that its users are easier to understand and comfortable using it

3) It is expected that users can only make one not double to save data space, so that data space is not wasted

\section{REFERENCES}

[1] C.J.Mitchel, A. a. (2015). Single Sign-On. Impostor: A Single Sign-On System for use from untrusted device , -7

[2] WSO2. (2020). gambar sistem single sign on. Diambil kembali dari wso2 identity server 5.9.0:

https://docs.wso2.com/download/attachments/49088428/image2018-10-29_11-25-19.

[3] WSO2. (2020). open source. hal.9 https://docs.wso2.com/display/IS510/Single+Sign-On

[4] WSO2. (2020). Installation. hal. https://is.docs.wso2.com/en/latest/setup/installationprerequisites/

[5] Mikolajczak, C. (2017, february 08). An Introduction to SAML (Security Assertion Markup Language). hal. https://www.secureauth.com/blog/an-introduction-to-samlsecurity-assertion-markup-language/. - 13

[6] Kirovska, N. a. (2015). Usage of Kanban methodology at software development teams. Journal of Applied Economics and Business, 13. 